\title{
RANCANG BANGUN BIBLIOGRAFI BERANOTASI DEBUS BANTEN
}

\author{
Fara Feranisa $^{1}$, Sukaesih $^{2}$, Wina Erwina ${ }^{3}$ \\ ${ }^{1}$ Dinas Kearsipan dan Perpustakaan Kabupaten Lebak, Banten \\ ${ }^{2,3}$ Prodi Ilmu Perpustakaan Fikom Unpad, Bandung \\ ${ }^{1}$ faraferanisa@gmail.com, ${ }^{2}$ sukaesihcicih09@yahoo.com, ${ }^{3}$ erwina.unpad@gmail.com
}

\begin{abstract}
This study is about designing of annotated bibliography Debus Banten used documentation activity step. The purpose of this study is to identifying elements of Debus culture, collecting information resources of Debus culture, knowing standard of cataloguing rules in Indonesia now, knowing classification type that commonly used to bibliography, knowing the rules of abstract for support manufacture of bibliography of Debus. The method used is action research, with designing of annotated bibliography of Debus. Data collecting technique used is observation, informal interviews, and publicities literature. Stage of making an annotated bibliography of Debus is identify Debus, collect information resources related to Debus. After that, designing a bibliography using the standard rules of bibliography in national library Republik Indonesia now, namely DDC 23 (classification) and AACR2 (cataloguing). This study resulted a product that is annotatded bibliography of Debus Banten. The annotatded bibliography of Debus has been tested public to student of faculty of Adab dan Humanities UIN Syarif Hidayatullah and the result is positif, bibliography of Debus can be used by information seekers.
\end{abstract}

Keyword: Annotated bibliography, documentation activity, Debus, Banten

ABSTRAK - Penelitian ini mengenai rancang bangun bibliografi beranotasi Debus Banten dengan menggunakan langkah-langkah kegiatan pendokumentasian. Tujuan penelitian ini adalah untuk mengidentifikasi unsur-unsur budaya Debus, mengumpulkan sumber informasi budaya Debus, mengetahui standar aturan katalogisasi di Indonesia saat ini, mengetahui jenis klasifikasi yang biasa digunakan untuk bibliografi, mengetahui aturan sari karangan guna menunjang pembuatan bibliografi Debus. Metode yang digunakan adalah penelitian tindakan, dengan merancang dan membangun bibliografi beranotasi Debus Banten. Teknik pengumpulan data yang digunakan yaitu observasi, wawancara informal dan studi pustaka. Tahapan merancang dan membuat sebuah bibliografi Debus yaitu diawali dengan mengidentifikasi kesenian Debus, mengumpulkan sumber informasi yang berkaitan dengan Debus. Setelah itu merangcang bibliografi dengan menggunakan aturan standar Bibliografi di perpustakaan nasional republik Indonesia saat ini, yaitu klasifikasi DDC 23 dan aturan katalogisasi AACR2. Penelitian ini menghasilkan sebuah produk dalam bentuk dokumen sekunder yaitu bibliografi Debus Banten yang telah diuji publik kepada mahasiswa fakultas adab dan humaniora UIN Syarif Hidayatullah dengan hasil yang positif yaitu bibliografi ini layak untuk digunakan oleh pencari informasi.

Kata Kunci: Bibliografi beranotasi, kegiatan pendokumentasian, Debus, Banten

\section{PENDAHULUAN}

Perkembangan dan perubahan informasi terjadi begitu cepat sehingga terjadi ledakan informasi. Hal tersebut menyebabkan informasi yang diperoleh sangat banyak dan beragam sehingga pencari informasi kesulitan menampung informasi tersebut. Selain itu, beragamnya informasi yang diperoleh perlu pengelompokan agar dapat ditemukan dengan cepat dan akurat. Oleh karena itu, perlu adanya suatu kegiatan pendokumentasian informasi.

Dokumentasi merupakan kegiatan mencatat dan merekam suatu data yang akan menjadi informasi, karena pada dasarnya informasi merupakan sebuah data yang telah diolah menjadi suatu bentuk yang memiliki nilai dan arti bagi pencari informasi. Selain itu, dokumentasi pun 
dapat diartikan sebagai pengumpulan, penyeleksian serta penyusunan suatu informasi. Tujuan dari dokumentasi akan menghasilkan suatu informasi dalam bentuk baru yang lebih terorganisir, agar dapat menjadi sebuah alat pengendalian informasi. Salah satu alat telusur informasi yang digunakan untuk pengendalian informasi yaitu bibliografi.

Bibliografi merupakan sebuah dokumen sekunder yang dibuat untuk merujuk ke dokumen primer. Menurut Sulistyo-Basuki (2004, 44), bibliografi adalah daftar artikel majalah, buku dan dokumen lain mengenai sebuah subjek atau beberapa subjek. Selain itu, pengertian lain bibliografi merupakan "daftar buku-buku dalam bidang atau suatu subyek tertentu, dimana hakikat keberadaan (lokasi) buku-buku yang tercantum di dalam bibliografi tadi tidak dibatasi pada satu perpustakaan" (Trimo: 1997, 150). Jadi, bibliografi merupakan dokumen sekunder yang berfungsi sebagai bahan rujukan untuk dokumen primer, di dalamnya berisi daftar dokumendokumen primer yang disusun secara sistematis menurut aturan bibliografi, dan dokumen primer tersebut lokasinya tidak terbatas pada satu perpustakaan.

Sumber informasi yang berkaitan dengan kesenian Debus sudah banyak didokumentasikan baik dalam bentuk tercetak maupun digital dan dalam jenis tertulis maupun rekaman video. Dokumen-dokumen dari sumber informasi tersebut dihasilkan melalui hasil penelitianpenelitian (penelitian mahasiswa, peneliti, instansi pemerintahan terkait), produk-produk dari katalog budaya yang dibuat oleh instansi pemerintahan, serta hasil liputan media berita. Dokumen tersebut terdapat dalam bentuk buku, rekaman video, leaflet, hasil penelitian (skripsi, tesis, disertasi dan artikel ilmiah), katalog budaya, ensiklopedia, dan artikel berita.

Debus merupakan kesenian yang berasal dari Provinsi Banten, sebagaimana pada tahun 2013 sebagai warisan budaya tak benda Indonesia dari Provinsi Banten. Debus telah diakui dunia sebagai Warisan Budaya Tak Benda oleh UNESCO melalui Kementerian Pendidikan dan Kebudayaan dikutip dari portal Okezone bahwa Kepala Dinas kebudayaan dan Pariwisata Provinsi Banten Endrawati menyampaikan "bahwa debus mendapat pengakuan ini sejak 11 Desember 2013" (Okezone: 2014). Selain itu, Seperti yang diungkapkan oleh Kepala Seksie Kesenian Dinas Budaya dan Pariwisata atau yang biasa disingkat dengan "Disbudpar" Provinsi Banten, yakni:

"Walaupun Debus ini ada di berbagai wilayah Indonesia dengan sebutan yang berbeda-beda, tetapi secara historical Debus merupakan tradisi sultan dari Banten. Pada zaman Sultan Maulana Hasanudin Debus merupakan sarana syiar untuk menyebarkan serta memperkenalkan agama dan budaya Islam, tetapi ketika zaman penjajahan Belanda, Debus ini digunakan oleh Sultan Ageng Tirtayasa sebagai penegak kedisiplinan serta memupuk keberanian rakyat." (Rohaendi diwawancarai oleh Fara Feranisa pada 08 Desember 2015, 09:29 WIB)

Jadi, kesenian Debus diakui berasal dari Banten karena Debus merupakan bagian dari sejarah Banten. Seperti yang sudah diungkapkan oleh Kepala Seksie Kesenian Disbudpar Banten, bahwa fungsi awal Debus merupakan sarana syiar agama Islam, penegak kedisiplinan ketika zaman penjajahan, dan saat ini berubah fungsi menjadi kesenian pertunjukan. 
Menurut Sandjin Aminuddin (1997, 156), kesenian tradisional Debus termasuk kepada jenis kesenian tradisional pertunjukan rakyat. Dilihat dari proses dan pelaksanaannya, kesenian Debus berkaitan erat dengan Islam, karena di dalamnya terdapat ritual-ritual tarekat yang menjadi tradisi Islam dalam Debus. Ciri khas dari kesenian ini yaitu mempertunjukan suatu bentuk kekebalan tubuh dari benda tajam. Selain itu, Debus Banten pun mempunyai ciri khas tersendiri yaitu alat yang digunakannya berupa al-madad.

Ketika proses Islamisasi hingga zaman kerajaan Islam di Banten yaitu zaman Maulana Hasanuddin, Debus digunakan untuk sarana penyebaran agama Islam. Ketika zaman penjajahan yaitu zaman Sultan Ageng Tirtayasa, Debus digunakan sebagai alat untuk membangkitkan semangat pejuang yang melawan penjajah. Saat ini Debus telah berubah fungsi menjadi salah satu bentuk kebudayaan takbenda (intangible) dari Banten yang berbentuk kesenian pertunjukan yang ditampilkan dengan tujuan untuk melestarikan dan untuk menarik penonton atau wisatawan datang. Dari penjelasan di atas dapat disimpulkan bahwa Debus merupakan produk sejarah yang beralih fungsi menjadi produk kesenian. Seperti yang diungkapkan oleh Kepala Seksie Kesenian Dinas Budaya dan Pariwisata Provinsi Banten, yakni

"Debus berubah fungsi mulai dari sarana syiar kemudian menjadi seni pertunjukan. kalo sarana syiar awalnya ada sarana ritual dan kemudian sekarang menjadi seni pertunjukan. Hampir semua tradisi-tradisi budaya di Indonesia sekarang berubah menjadi seni pertunjukan karena kebutuhannya sudah lagi bukan untuk ritual atau syiar karena sudah beda zaman dan sudah banyak media yang lebih efektif untuk menyebarkan Islam dan syiar." (Rohaendi diwawancarai oleh Fara Feranisa pada 08 Desember 2015, 09:29 WIB)

Dilihat dari wujudnya Debus merupakan warisan budaya tak benda atau sesuatu yang tidak dapat diraba (intangible), karena Debus merupakan budaya dalam bentuk pertunjukkan kesenian tradisional. Seperti yang diungkapkan oleh Taylor (1897) bahwa "kebudayaan meliputi pemahaman perasaan suatu bangsa yang kompleks, meliputi pengetahuan, kepercayaan, seni, moral, hukum, adat-istiadat (kebiasaan), dan pembawaaan lainnya yang diperoleh dari anggota masyarakat" (dalam Soelaeman 2007, 19). Dari pengertian tersebut menyatakan bahwa suatu kesenian merupakan bagian yang terdapat dalam budaya.

Debus merupakan kesenian yang sudah ada sejak zaman kerajaan Islam Banten hingga sekarang. Walaupun fungsinya berbeda, tetapi kesenian ini masih tetap eksis dan disukai oleh masyarakat sehingga menjadi kemasan seni pertunjukan saat ini. Sanggar Debus di Banten terdapat 24 buah yang tedaftar pada RIPKD (Rencana Induk Pelestarian Kebudayaan Daerah) Provinsi Banten 2013-2027. Sanggar debus tersebut ada di beberapa wilayah Banten yakni 2 di Kabupaten Tangerang, 1 di Kota Tangerang, 5 di Kabupaten Lebak, 8 di Kabupaten Pandeglang, 2 di Kabupaten Serang, 1 di Kota Cilegon, dan 5 di Kota Serang.

Banten merupakan provinsi yang terletak di ujung paling barat Pulau Jawa. Provinsi ini merupakan daerah hasil pemekaran dari Provinsi Jawa Barat. Secara resmi pada tanggal 17 Oktober 2000 wilayah Banten dimekarkan dari Provinsi 
Jawa Barat dan menjadi provinsi ke-28 di Indonesia. Wilayah Banten dengan Ibu Kota Serang dibagi menjadi 4 kota dan 4 kabupaten. Budaya yang terdapat pada Provinsi Banten sangatlah beragam mulai dari bahasa, kepercayaan, adat istiadat, tradisi ritual, serta kesenian.

Banten dikenal dengan seni beladiri, kekuatan fisik, kesaktian seperti kekebalan tubuh dari senjata tajam. Kesenian Debus memang sudah menjadi trademark Provinsi Banten, kesenian ini mencirikan masyarakat Banten yang energik dan religius karena pertunjukan Debus diawali oleh dzikir dan ritual keagamaan lainnya. Debus merupakan sebuah kesenian tradisional dalam bentuk pertunjukan yang ekstreme dan berbahaya, pertunjukan Debus ini hanya dilakukan oleh orang-orang yang sudah terlatih.

Bibliografi sebagai sarana pengendalian informasi mengenai kesenian Debus menjadi penting untuk sebuah studi mengenai kesenian tersebut. Oleh karena dalam penelitian ini bermaksud untuk membuat dokumen sekunder dari kesenian Debus guna memudahkan pencari informasi Debus untuk dapat menemukan informasi mengenai kesenian Debus. Dokumen sekunder yang akan dibuat yaitu dalam bentuk bibliografi beranotasi.

Bibliografi beranotasi Debus merupakan dokumen sekunder yang di dalamnya berisi daftar bahan pustaka yang berkaitan dengan kesenian Debus, yang dibuat dengan tujuan untuk temu kembali informasi mengenai Debus. Langkahlangkah yang digunakan untuk membuat bibliografi ini mengikuti langkah dari kegiatan pendokumentasian. Kegiatan dokumentasi dalam perpustakaan

merupakan

kegiatan

pengorganisasian, pengumpulan, penyimpanan suatu informasi. Seperti pengertian dokumentasi yang diungkapkan oleh Paul Otlet yaitu "Documentation is the collection, arrangement, and distribution of documents of every sort in all fields of human activity" (dalam Sulistyo-Basuki: 2004, 6). Dari pengertian tersebut dokumentasi dalam perpustakaan merupakan suatu pengumpulan, penyusunan dan penyaluran setiap jenis dokumen dalam setiap kegiatan manusia. Jika dihubungkan dengan budaya maka dalam hal ini dapat disimpulkan bahwa dokumentasi budaya merupakan suatu bentuk kegiatan pengumpulan, pengorganisasian, penyusunan penyimpanan, temu kembali, serta penyebaran informasi dari budaya tersebut.

Kegiatan pendokumentasian budaya Debus ini dilakukan dengan cara mengumpulkan, menyeleksi, serta menyusun informasi dari Debus tersebut. Informasi yang berkaitan dengan Debus didokumentasikan agar dapat terekam dan tersimpan supaya informasi tersebut dapat lebih terorganisir. Infomasi dari kesenian Debus yang sudah didokumentasikan dapat memudahkan pencari informasi dalam menemukan informasi mengenai kesenian Debus. Jadi, dapat disimpulkan bahwa kesenian Debus didokumentasikan untuk mempermudah seorang peneliti budaya atau pencari informasi dalam menemukan kembali informasi mengenai kesenian Debus.

Proses pembuatan bibliografi beranotasi Debus dilakukan dengan cara mengumpulkan informasi-informasi yang berkaitan. Sumber informasi yang dikumpulkan diperoleh melalui 
personal, institusi, dan media. Personal yaitu orang yang paham mengenai Debus, selain itu dapat juga diperoleh dari komunitas atau pendiri sanggar debus. Institusi yaitu lembaga kedinasan yang berkaitan dengan budaya atau lembaga informasi. Melalui media yaitu mengakses sistem jaringan informasi dan repository dari universitas yang pernah meneliti tentang kesenian Debus.

Berdasarkan penjelasan di atas, maka dalam penelitian ini peneliti tertarik untuk membuat suatu rancang bangun bibliografi beranotasi Debus Banten. Rancang bangun tersebut dibuat dengan langkah-langkah kegiatan pendokumentasian. Tujuan dari pembuatan bibliografi ini untuk memberikan fasilitas bagi pencari informasi mengenai kesenian Debus di Banten.

\section{TINJAUAN PUSTAKA}

Kebudayaan meliputi pemahaman perasaan suatu bangsa yang kompleks, meliputi pengetahuan, kepercayaan, seni, moral, hukum, adat-istiadat (kebiasaan), dan pembawaaan lainnya yang diperoleh dari anggota masyarakat (Taylor dalam Soelaeman: 2007, 19). Menurut konsep B. Malinowski, kebudayaan di dunia mempunyai tujuh unsur universal, yaitu "bahasa, sistem teknologi, sistem mata pencaharian, organisasi sosial, sistem pengetahuan, religi, dan kesenian" (Soelaeman: 2007, 23).

Menurut Sandjin Aminuddin (1997, 156), kesenian tradisional Debus termasuk kepada jenis kesenian tradisional pertunjukan rakyat, kesenian merupakan salah satu unsur dari ketujuh unsur kebudayaan menurut konsep B Malinowski. Dalam penelitian ini yang menjadi titik utama kegiatan pendokumentasi yaitu informasi mengenai kesenian Debus. Sumber informasi yang akan didokumentasikan dalam bentuk dokumen.

Dokumen artinya objek yang merekam informasi dengan tidak memandang media maupun bentuknya. Dokumen merupakan wadah yang menyimpan pengetahuan dan ingatan manusia karena pada dokumen tersimpan segala pengetahuan manusia serta ingatan manusia (Sulistyo-Basuki 2004, 23). Dokumen mempunyai fungsi sebagai sumber informasi. Jika dokumendokumen tersebut didokumentasikan maka akan lahir sebuah dokumen sekunder sebagai sebuah rujukan bagi pencari informasi. Dokumen sekunder memiliki arti "dokumen rujukan yang berisi informasi mengenai dokumen primer ataupun dokumen berupa bibliografi mengenai dokumen primer" (Sulistyo-Basuki 2004, 39).

Pekerjaan dokumentasi berkaitan dengan teknik pengumpulan, pengkatalogan, klasifikasi dan pembuatan abstrak literatur yang diterbitkan maupun tidak diterbitkan sedangkan jasa dokumentasi adalah proses menemukan materi yang tersedia dan menyajikannya bagi pemakai. Pekerjaan dokumentasi terdiri dari proses berikut: (Sulistyo-Basuki 2004, 16)

1. Menentukan lokasi dokumen dari berbagai sumber yang terbit dan tidak diterbitkan dengan melakukan penelusuran literatur.

2. Mengabstrak dokumen terutama literatur ilmiah yang mutakhir.

3. Mengklasifikasi dokumen dan abstrak dalam cara yang mudah bagi pemakai.

4. Mengindeks dokumen 
5. Merekam sehingga hasilnya dapat disebarluaskan untuk pemakai.

Dalam kegiatan pendokumentasian tersebut selanjutnya akan menghasilkan informasi dalam bentuk baru yaitu dokumen sekunder dalam bentuk bibliografi beranotasi. Bibliografi memiliki arti daftar bahan pustaka yang disusun secara sistematis mengikuti standar aturan yang berlaku untuk pembuatan bibliografi. Menurut SulistyoBasuki $(2004,44)$, bibliografi adalah daftar artikel majalah, buku dan dokumen lain mengenai sebuah subjek atau beberapa subjek. Pengertian lain yaitu "bibliografi adalah daftar buku-buku dalam bidang atau suatu subyek tertentu, dimana hakikat keberadaan (lokasi) buku-buku yang tercantum di dalam bibliografi tadi tidak dibatasi pada satu perpustakaan" (Trimo 1997, 150). Sedangkan anotasi merupakan sari karangan atau informasi isi bahan pustaka yang disajikan ringkas namun jelas dan lengkap mewakili isi dari bahan pustaka tersebut. Anotasi memiliki arti "catatan yang ditambahkan pada informasi judul atau informasi bibliografis sebuah dokumen dengan cara komentar atau penjelasan” (Sulistyo-Basuki 2004, 184). Jadi, bibliografi beranotasi dapat diartikan sebagai daftar dokumen-dokumen primer yang biasanya tersediri dari satu subyek atau lebih yang disusun secara sistematis dan diikuti oleh anotasi atau sari karangan yang berfungsi sebagai penjelasan isi dari dokumen tersebut.

\section{METODE PENELITIAN}

Penelitian rancang bangun bibliografi beranotasi Debus Banten ini menggunakan metode penelitian kualitatif. Metode penelitian kualitatif dipilih karena untuk memecahkan suatu permasalahan dalam penelitian ini diperlukan cara-cara kualitatif. Selain itu, penelitian ini pun menggunakan metode action research. Action research atau penelitian tindakan ini digunakan karena untuk menghasilkan suatu produk dalam bentuk bibliografi beranotasi Debus.

\section{HASIL DAN PEMBAHASAN}

Pada proses pembuatan rancangan bibliografi beranotasi Debus Banten ini menggunakan langkah-langkah kegiatan pendokumentasian. Konsep yang digunakan yaitu menggunakan langkah-langkah pekerjaan dokumentasi (Sulistyo-Basuki: 2004, 16). Pekerjaan dokumentasi berkaitan dengan teknik pengumpulan, pengkatalogan, klasifikasi dan pembuatan abstrak literatur yang diterbitkan maupun tidak diterbitkan. Namun sebelum melangkah kepada langkah-langkah pekerjaan dokumentasi tersebut terlebih dahulu mengidentifikasi budaya (kesenian Debus).

1. Identifikasi Kesenian Debus Banten. Proses pengidentifikasian kesenian Debus merupakan proses untuk mengetahui lebih lanjut atau mengenal kesenian Debus Banten. Hal ini dilakukan untuk mempermudah dalam proses selanjutnya yaitu penentuan subyek bahan pustaka apa saja yang seharusnya dikumpulkan. Pengidentifikasian tersebut meliputi komponen kesenian Debus, asal usul atau sejarah kesenian Debus dan tarekat yang terkandung dalam kesenian Debus.

$\begin{array}{lrr}\text { Pada komponen } & \text { kesenian } & \text { Debus, } \\ \text { pengidentifikasiannya } & \text { meliputi } & \text { segala }\end{array}$


sesuatu yang berhubungan dengan kesenian Debus. Hal tersebut adalah

a. Makna dan pengertian Debus

b. Perlengkapan Debus, yang dibagi lagi menjadi alat utama Debus, alat musik dan pakaian

c. Pertunjukan Debus

Pengidentifikasi pada asal-usul atau sejarah Debus meliputi sejarah Debus pada awal diperkenalkan, berkembang, dan saat ini. Identifikasi pada asal-usul Debus adalah

a. Debus digunakan sebagai sarana syiar Islam pada zaman Maulana Hasanuddin

b. Debus digunakan sebagai propaganda perang dan memompa semangat para pejuang Banten pada masa penjajahan ketika zaman Sultan Ageng Tirtayasa

c. Saat ini Debus merupakan budaya tak benda yang berasal dari Banten dalam bentuk kesenian pertunjukan tradisional

Debus sangat erat kaitannya dengan tradisi Islam, tradisi Islam dalam Debus diketahui berasal dari tarekat. Tarekat yang terkandung dalam Debus diketahui ada 2 jenis tarekat, yakni

a. Tarekat Qadariyah yang didirikan oleh Syeikh Abdul Qadir Jaelani

b. Tarekat Rifaiyah yang didirikan oleh Ahmad Rifa'i

2. Sumber informasi yang ditemukan dan dikumpulkan dalam proses rancang bangun bibliografi beranotasi Debus Banten ini merupakan sumber informasi yang berkaitan dengan kesenian Debus. Sumber informasi yang dikumpulkan tersebut sesuai dengan proses pengidentifikasian kesenian Debus sebelumnya. Sumber informasi tersebut meliputi buku, laporan penelitian, skripsi, tesis, disertasi, jurnal, rekaman video, dan berita mengenai debus. Informasi tersebut diperoleh melalui lembaga informasi seperti perpustakaan, museum, dinas yang bersangkutan dengan budaya serta repository atau digital library perguruan tinggi dan perpustakaan digital lainnya.

3. Rancang Bangun Bibliografi Beranotasi Debus Banten

Bibliografi beranotasi Debus Banten ini termasuk ke dalam bibliografi subjek, karena bibliografi ini hanya mendaftar bahan-bahan pustaka yang berhubungan dengan kesenian Debus Banten saja. Produk ini memang dititikberatkan pada bibliografi tetapi dalam bibliografi ini peneliti memberikan beberapa uraian penjelasan mengenai Debus Banten di dalamnya.

Bibliografi ini dibagi menjadi tiga bagian yaitu kesenian tradisional Debus, sejarah Debus, dan tarekat. Bagian-bagian tersebut diawali dengan penjelasan Debus, setelah itu terdapat daftar bahan pustaka yang berhubungan setiap pokok bahasan pada bagiannya. Alur proses pembuatan rancang bangun bibliografi beranotasi Debus Banten berdasarkan alur kerja teknis penyusunan naskah bibliografi (PNRI) dan modifikasi peneliti. Berikut bagan alur kerja proses pembuatan rancang bangun bibliografi beranotasi Debus Banten. 


\section{Bagan 1}

Alur proses pembuatan rancang bangun bibliografi beranotasi Debus Banten berdasarkan alur kerja teknis penyusunan naskah bibliografi

(PNRI) dan modifikasi peneliti

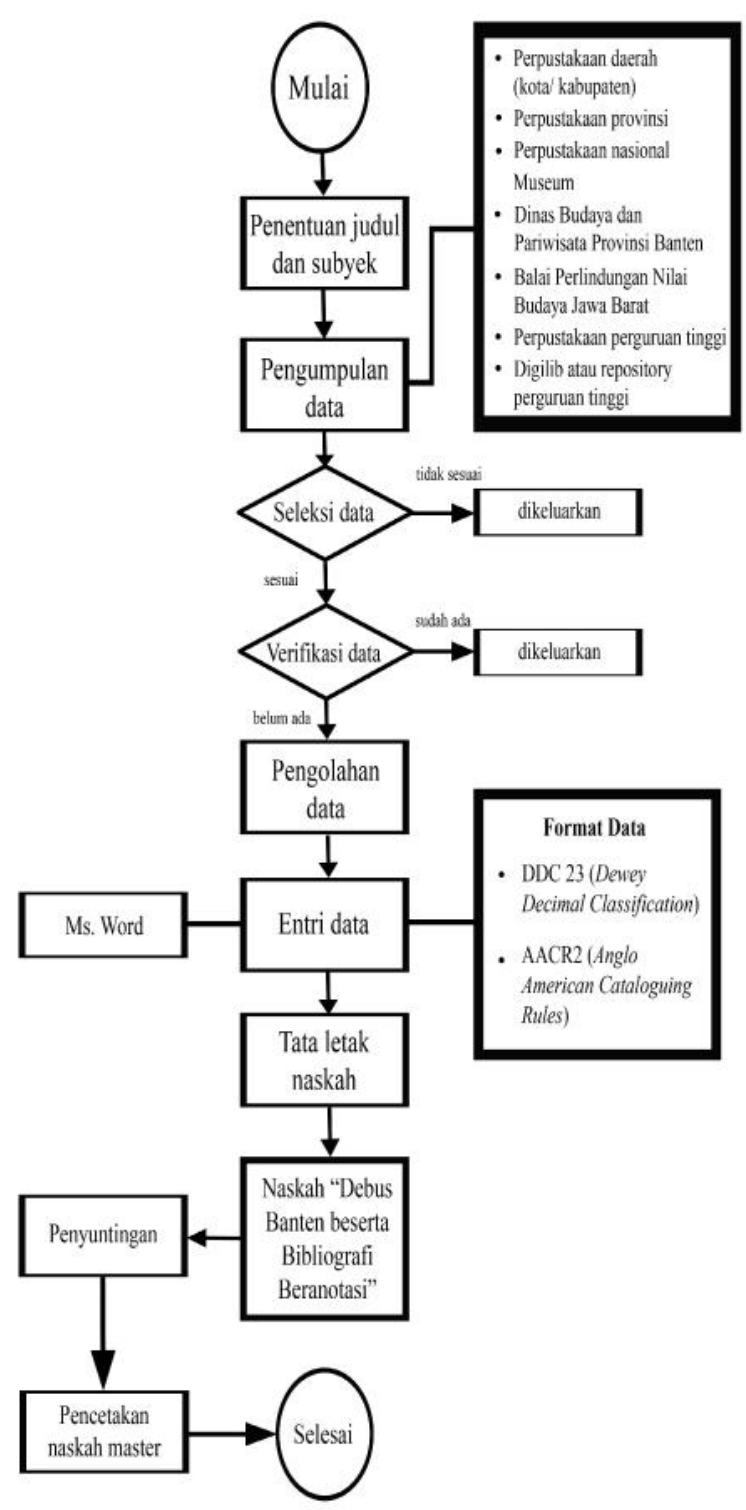

a. Penentuan Judul dan Subyek

Judul yang diberikan dalam pembuatan bibliografi ini adalah "Debus Banten (Bibliografi Beranotasi)". Judul tersebut dipilih karena objek dari pembuatan rancang bangun bibliografi ini adalah Debus. Debus dipilih karena merupakan suatu objek budaya yang sudah banyak diteliti sehingga banyak para peneliti yang tertarik meneliti kesenian Debus tersebut. Selain itu, sumber informasi yang berkaitan dengan Debus sudah cukup banyak sehingga diperlukan suatu pengendalian informasi Debus dalam bentuk bibliografi agar mudah untuk proses temu kembali informasi mengenai Debus. Penentuan subyek dalam rancang bangun bibliografi ini berkaitan dengan proses pengidentifikasian Debus sebelumnya.

Bibliografi ini dibagi menjadi 3 bagian yakni

Bagian pertama, Kesenian Debus Banten yang meliputi makna dan pengertian Debus, pencaksilat, perlengkapan Debus [ alat utama (almadad), musik (terebang gede/ rebana), pakaian (baju kampret, celana pangsi, dan lomar/ ikat kepala) ], pertunjukan Debus.

Bagian Kedua, Sejarah atau Asal Usul Debus Banten yang meliputi proses Islamisasi dan kerajaan Islam di Banten (Maulana Hasanuddin), Zaman Penjajahan di Banten (Sultan Ageng Tirtayasa).

Bagian Ketiga, Tarekat yang terkandung di Debus yang meliputi tarekat Qadariyah (Abdul Qadir Jaelani) dan tarekat Rifa'iyah (Ahmad Rifa'i).

Dari setiap bagian-bagian tadi terdapat beberapa pembahasan yang akan menjadi acuan penentuan subyek dalam mencari sumber informasi yang berkaitan dengan Debus untuk disusun menjadi sebuah bibliografi beranotasi.

b. Penentuan Judul dan Subyek

Proses pengumpulan data untuk membuat rancang bangun bibliografi beranotasi Debus ini yaitu dengan cara penelusuran informasi ke 
berbagai lembaga informasi, baik lembaga informasi yang berbentuk digital maupun konvensional. Lembaga-lembaga informasi tersebut terdiri dari:

1. Perpustakaan-perpustakaan daerah yang ada di Provinsi Banten

2. Badan Perpustakaan dan Arsip Provinsi Banten

3. Badan Perpustakaan dan Arsip Provinsi Jawa Barat

4. Balai Perlindungan Nilai Budaya Jawa Barat

5. Dinas Budaya dan Pariwisata Provinsi Banten

6. E-resources Perpustakaan Nasional Republik Indonesia

7. Naskah kuno Sribaduga

8. Perpustakaan Museum Nasional

9. Perpustakaan Nasional Republik Indonesia

10. Perpustakaan-perpustakaan perguruan tinggi (baik mengakses secara konvensional maupun digital)

11. Portal berita online.

Bahan pustaka yang terkumpul ada dalam berbagai jenis, diantaranya buku, hasil penelitian (skripsi, tesis, disertasi, jurnal, laporan penelitian, rekaman video, artikel berita, E-book, E-journal).

c. Seleksi data

Bahan pustaka yang sudah ditemukan akan diseleksi. Proses penyeleksian ini berfungsi untuk mengetahui sesuai atau tidak bahan pustaka yang diperoleh dengan Debus, karena bibliografi ini merupakan bibliografi subyek yang hanya mencakup subyek-subyek yang berkaitan dengan Debus yang sudah ditentukan sebelumnya.

d. Verifikasi data

Verifikasi merupakan proses pemeriksaan bahan pustaka pada pangkalan data, hal ini dilakukan agar mencegah suatu duplikasi bahan pustaka ketika dientri.

e. Pengolahan data

Setelah lolos tahap verifikasi, selanjutnya bahan pustaka diolah dengan cara mengidentikasi deskripsi bibliografis pada bahan pustaka tersebut.

f. Entri data

Setelah bahan pustaka diolah, langkah selanjutnya yakni proses entri data. Proses entri data ini segala deskripsi bibliografis bahan pustaka dimasukkan ke dalam pangkalan data, mulai dari nomor klasifikasi, judul, lokasi bahan pustaka tersebut berada, hingga anotasi., menurut Sulistyo-Basuki pangkalan data adalah kumpulan cantuman (records) sejenis dengan hubungan yang jelas antara cantuman tersebut (Sulistyo-Basuki : 2004, 289).

g. Format data

Format data yang digunakan dalam pembuatan bibliografi ini menggunakan aturan klasifikasi DDC 23 (Dewey Decimal Classification), aturan katalogisasi AACR2 (Anglo American Cataloguing Rules) dan sari karangan berupa anotasi.

Selain entri bibliografi, dalam bibliografi ini terdapat indeks yang dibuat untuk mempermudah pencarian bibliografi. Indeks tersebut dibagi menjadi tiga yakni indeks judul, 
pengarang serta subyek. Indeks tersebut disusun berdasarkan abjad dan diacukan ke nomor klasifikasi.

\section{Gambar 1}

\section{Contoh entri dan indeks judul pada}

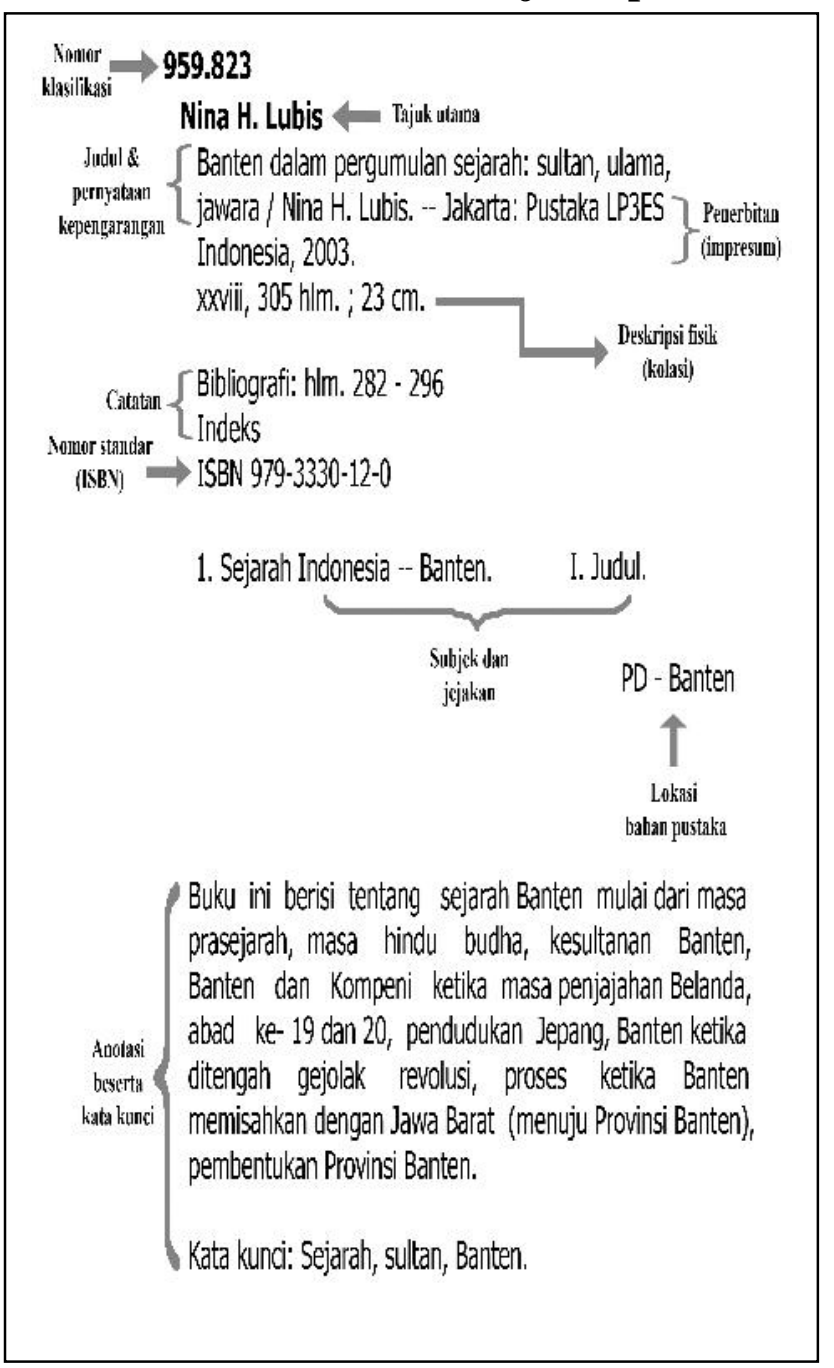

h. Tata letak naskah

Tata letak rancang bangun bibliografi beranotasi Debus Banten ini dibagi menjadi empat bagian, sebagai berikut:

1. Cover atau halaman judul

2. Bagian pendahuluan/ awal
a. Kata pengantar
b. Daftar isi
c. Daftar situs web dan lembaga informasi.
Berisi daftar lembaga informasi tempat diperolehnya sumber informasi

bibliografi Debus. Daftar tersebut pun dilengkapi dengan alamat website sehingga mempermudah pengguna untuk mencari secara virtual dalam browser.

d. Petunjuk penggunaan

3. Isi

Bagian isi dibagi menjadi tiga bagian yakni kesenian tradisional Debus, sejarah Debus, dan tarekat. Pada tiap-tiap bagian berisi uraian penjelasan setelah itu daftar entri bahan pustaka (bibliografi). Selain itu, pada bagian isi terdapat indeks. Indeks ini dibagi menjadi tiga, yakni indeks pengarang, judul, dan subjek.

\section{Bagian Akhir}

Pada bagian akhir terdapat daftar nama-nama sanggar atau padepokan yang terdapat di Provinsi Banten. Setelah itu, terakhir terdapat daftar pustaka dari sumber-sumber yang peneliti gunakan dalam uraian penjelasan tiap-tiap bagian.

\section{i. Penyuntingan}

Tahap penyuntingan ini dilakukan dengan cara melihat kembali dari mulai cover hingga daftar pustaka. Selain itu, peneliti pun mencoba menguji indeks yang telah dibuat.

Tahap ini pun merupakan tahap untuk mengujikan produk pada ahli atau memverifikasi lebih lanjut informasi yang terkandung pada bibliografi dan format penulisan bibliografi. Bibliografi beranotasi Debus diujikan kepada ahli kesenian dan bibliografi. Setelah itu, bila masih ada informasi atau format yang kurang tepat maka bibliografi akan diperbaiki terlebih dahulu sebelum dicetak. 


\section{j. Pencetakan Naskah Master}

Pada tahap pencetakan, bibliografi dicetak dengan hardcover. Pada bagian isi bibliografi dicetak bolak-balik seperti buku pada umumnya, sedangkan pada bagian awal/ pendahuluan dan bagian akhir bibliografi hanya dicetak satu muka.

\section{PENGUJIAN BIBLIOGRAFI}

Pengujian bibliografi ini dibagi menjadi 2 bagian yakni pengujian kepada ahli dan pengujian kepada publik. Dalam pengujian kepada ahli, ahli yang peneliti pilih yakni ahli dalam bidang budaya (kesenian) dan bidang bibliografi. Pengujian bibliografi pada publik, publik yang dipilih yaitu para pencari informasi di Fakultas Adab dan Humaniora, Universitas Islam Negeri Syarif Hidayatullah.

\section{Pengujian Ahli}

Hasil dari pengujian ahli budaya (kesenian) menyatakan bahwa informasi Debus yang terdapat pada bibliografi sudah lengkap dan isi informasi sudah sesuai. Namun ada beberapa saran bahwa lebih merinci akan istilah-istilah pada kesenian Debus. Pada bagian sejarah, perlu ditambahkan lagi mengenai sejarah Debus di masa kini.

Hasil pengujian pada ahli bibliografi masih banyak kekurangan yakni terdapat klasifikasi yang belum tepat yakni ada beberapa cantuman yang masih menggunakan versi DDC dahulu bukan DDC 23, penulisan nama pengarang yang seharusnya tidak dibalik untuk nama Indonesia dan saran untuk meringkas anotasi.

2.Pengujian Publik
Pada pengujian publik, peneliti mengujikan produk bibliografi beranotasi Debus Banten disertai dengan penyebaran kuesioner pada 30 mahasiswa Fakultas Adab dan Humaniora UIN Syarif Hidayatullah. Pertanyaan kuesioner tersebut diambil dari beberapa fungsi bibliografi dan komponen-komponen yang ada dalam bibliografi tersebut. Kuesioner ini dibuat untuk mengetahui apakah bibliografi tersebut layak untuk dimanfaatkan atau tidak. Hasil dari kuesioner tersebut disajikan dalam bentuk persen, dalam artikel ini peneliti hanya menyajikan hasil yang paling tinggi dari setiap bagiannya. Berikut:

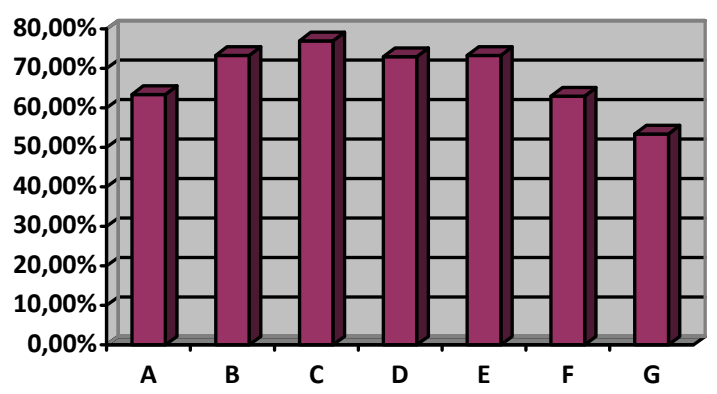

Keterangan:

$\mathrm{A}=$ Kemudahan penggunaan bibliografi Debus

$\mathrm{B}=$ Kejelasan nomor klasifikasi bibliografi Debus

$\mathrm{C}=$ Kejelasan deskripsi bahan pustaka pada bibliografi Debus

$\mathrm{D}=$ Kejelasan anotasi pada bibliografi Debus

$\mathrm{E}=$ Kejelasan lokasi bahan pustaka pada bibliografi Debus

$\mathrm{F}=$ Bibliografi Debus membantu pencarian informasi Debus

$\mathrm{G}=$ Penghematan atau efisiensi waktu dalam pencarian informasi

Kesimpulan dari pengujian publik ini, bibliografi mendapatkan hasil yang positif dan dapat 
dikatakan bahwa bibliografi beranotasi Debus Banten layak untuk digunakan.

\section{SIMPULAN}

1. Tahap identifikasi budaya merupakan tahap mengetahui dan mengenali budaya tersebut. Identifikasi Debus Banten merupakan tahap untuk mengenali kesenian Debus yang meliputi makna, tujuan, peralatan dan perlengkapan, ritual serta unsur-unsur lain yang berkaitan dengan Debus Banten.

2. Tahap pengumpulan sumber informasi budaya merupakan tahap mengumpulkan segala bentuk sumber informasi baik dalam bentuk tulisan, audiovisual, digital, maupun nondigital. Tahap pengumpulan sumber informasi Debus merupakan tahap penelusuran serta pengumpulan sumber informasi yang berkaitan dengan Debus yang meliputi buku, transliterasi naskah kuno, laporan penelitian, skripsi, tesis, disertasi, jurnal, rekaman video, dan berita mengenai Debus. Informasi tersebut ditelusur melalui perpustakaan kabupaten/ kota, perpustakaan provinsi, perpustakaan nasional, perpustakaan museum, perpustakaan perguruan tinggi, koleksi naskah kuno museum, repository atau perpustakaan digital perguruan tinggi, dan media massa.

3.Klasifikasi yang digunakan dalam pembuatan bibliografi Debus Banten adalah klasifikasi DDC 23 (Dewey Decimal Classification), karena klasifikasi DDC merupakan jenis klasifikasi yang paling banyak digunakan di perpustakaan di Indonesia sehingga klasifikasi ini sudah dikenal di Indonesia.
4.Format aturan katalogisasi yang digunakan untuk pembuatan bibliografi Debus Banten mengikuti format dari bagian Bibliografi di Direktorat Deposit Perpustakaan Nasional Republik Indonesia yaitu menggunakan aturan katalogisasi AACR2 (Anglo-American Cataloguing Rules second edition) yang merupakan standard aturan katalog yang digunakan di Indonesia saat ini.

5.Pembuatan sari karangan yang dibuat dalam penyusunan bibliografi Debus ini merupakan sari karangan yang berjenis informatif yaitu sari karangan dengan bentuk penyajian mendeskripsikan serta menginformasikan bahan pustaka secara ringkas namun mencakup semua informasi yang terkandung di dalam bahan pustaka tersebut.

\section{DAFTAR PUSTAKA}

Aminudin, S. (1997). Kesenian Rakyat Banten dalam buku Banten Kota Pelabuhan Jalan Sutra. Penyunting Sri Sutjianingsih hlm. 153-165. Jakarta: Depdikbud.

Dinas Kebudayaan dan Pariwisata Provinsi Banten. (2012). "Rencana Induk Pelestarian Kebudayaan Daerah (RIPKD) Provinsi Banten 2013-2027. Serang: Disbudpar Provinsi Banten.

Okezone. (2014). Debus Sudah Diakui Dunia. Diakses dari http://lifestyle.okezone.com/read/2014/08/ 23/407/1028896/debus-sudah-diakuidunia.

Rohaendi. (08 Desember 2015). Wawancara pribadi. 
Soelaeman, M. M. (2007). Ilmu Budaya Dasar Trimo, S. (1997). Buku Paduan untuk Mata Suatu Pengantar. Bandung: Refika Kuliah Reference Work \& Bibliography Aditama. dengan sistem modular. Jakarta: Bumi Sulistyo-Basuki. (2004). Pengantar Dokumentasi. Aksara.

Bandung: Rekayasa Sains. 
